\title{
Words That Start With E: Why Librarians Should Fight Climate Change and Climate Change Denial
}

\section{Jennifer McDevitt ${ }^{1}$}

${ }^{1}$ School of Library and Information Studies, University of Alberta, Email: mcdevitt@ualberta.ca

\author{
To Cite:
}

McDevitt, J. (2020). Words that start with E: Why librarians should fight climate change and climate change. [Special Issue]. Pathfinder: A Canadian Journal for Information Science Students and Early Career Professionals, 1(1), 10-16.

\begin{abstract}
Ecology, economy, equity. Exemplars, educators, enablers. Librarianship centers around the values of community-building, access to information, and advocating for the public good, and so librarians are poised to be leaders when it comes to environmentally friendly and sustainable practices and policies. Our commitment to intellectual freedom demands that we ensure facts about climate change reach the public, while social responsibility asks that we consider the harm that can be done by the spread of disinformation like climate change denial-the kind of harm that has led to the devastating, irreversible circumstances we're in today. To ensure there will continue to be a community for libraries to serve, librarians must allow sustainability to underpin all their choices, especially with regard to educating the public, devaluing disinformation, and advocating for concrete collective action.
\end{abstract}

Keywords: climate change, disinformation, sustainability, collective action, social responsibility

cology, economy, equity. Exemplars, educators, enablers. These words are the first step to understanding the role of librarianship in fighting climate change and climate change denial. Librarianship centres around the values of community-building, access to information, and advocating for the public good. Intellectual freedom demands that all perspectives should be free from censorship; indeed, it is censorship that has prevented facts about climate change from reaching the public on numerous occasions. Social responsibility asks us to consider the harm that can be done by the spread of disinformation like climate change denial—-the kind of harm that has led to the

DOI:

(C) The Author(s) 2020 
irreversible circumstances we find ourselves in regarding climate change today. To ensure there will continue to be a community for libraries to serve, librarians must allow the ideology of sustainability to underpin all their choices, especially with regard to educating the public, devaluing disinformation, and advocating for collective action.

\section{The Reality of Climate Change}

Climate change is hardly a new concept, though it is becoming increasingly grim. Data collected since 1957 confirmed in 1979 that humans have altered, and continue to alter, the Earth's atmosphere by emitting greenhouse gases, most predominantly carbon dioxide from burning fossil fuels (Rich, 2018). Despite emission-reduction agreements like the 1997 Kyoto Protocol and the 2016 Paris Agreement, governments have continued to fail to reach an effective consensus on combating climate change (Rich, 2018). Long-term disaster is now the best case scenario, as the Earth warming by two degrees Celsius is almost guaranteed (Rich, 2018). Understanding the science behind climate change, making policies to reduce emissions, and innovating ways to fulfill those policies is not work that can be done by individuals alone. It falls to each of us to use our roles within the system of society to ensure collective action is taken.

\section{Sustainability as an Ideology}

Like scientific knowledge of climate change itself, the green library movement and the concepts of environmental and ecological literacy are not new, appearing in research in the early 1990s (Hauke, 2018). However, it is important to acknowledge that "sustainable" does not equate with "green" or "environmentally-friendly". Sustainability refers to an ideology best defined by what it is not: "A practice, relationship, or institution is not sustainable if it undermines the social, economic, or environmental condition of its own viability" (Thiele, 2016, p. 12-3). Sustainability is often thought of in terms of ecology, equity, and economy, as these concepts are so interwoven that fixing issues in one area without considering the others often serves only to cause more problems (Henk, 2014). As such, we cannot expect to see systemic change from piecemeal green choices, especially as they can become unsustainable as technology evolves (Barbakoff, 2012). 


\section{Influence of Climate Change on Libraries}

In September of 2018, the International Federation of Library Associations and Institutions (IFLA) published a document providing examples of how libraries serve as "exemplars, educators, and enablers" of sustainability. Prior to that, the American Library Association (ALA)'s 2015 "Resolution on the Importance of Sustainable Libraries" encouraged its membership to proactively apply sustainable thinking "in the areas of their facilities, operations, policy, technology, programming, partnerships and library school curricula." In January 2017, the ALA adopted the "Resolution on Access to Accurate Information", which affirms their 2005 "Resolution on Disinformation, Media Manipulation \& the Destruction of Public Information". In this resolution, ALA provides a lengthy definition of 'disinformation' that includes propaganda, fake news, distortions of truth, and the suppression of scientific studies and data (American Library Association, 2017). The ALA argues that "access to accurate information, not censorship, is the best way to counter disinformation and media manipulation" and supports librarians in their endeavours to teach information literacy. In June 2017, ALA specifically made note of the American presidential administration's removal of data and information files regarding global climate change from government websites and asserted that librarians have a commitment to the preservation and availability of that factual scientific data. These resolutions imply that the role of libraries is not to give a platform to anti-science and disinformation, but they also emphasize that censorship is not the answer. The conflict between these two directives presents librarians with a difficult balance to achieve.

\section{Role of Libraries in Fighting Back}

Preventing climate change from becoming worse may seem an impossibly large task-hardly something the average librarian can possibly hope to influence. However, the reality is that our collective actions have resulted in this situation, and it is our collective actions that will have an impact on the future. As a profession steeped in advocacy, librarianship must be vocal. As it is, "the system as it exists shelters us from the true consequences of our collective actions ... We live in a blissful ignorance that insulates us from the physical and social reality of our information system" (Henk, 2014). Our role as librarians is to stop living in that ignorance ourselves, do everything 
we can to ensure we tear the blinders off as many people as possible, and use our influence to help those people integrate direct action into their everyday lives.

\section{Devaluing Disinformation}

In addition to combating climate change itself, librarians are at the forefront of the fight against climate change denial. Disinformation and climate change denial is rampant (Hargar, 2016). These beliefs are intrinsically tied to the economy, especially in industries that rely on fossil fuels. Libraries, especially those funded by public dollars, are hardly free from the demands of capitalism. However, libraries already oppose the neoliberal drive to solely consider the bottom line by providing shared services and materials. As librarians, ensuring access to facts is the least we can do to combat disinformation. Our core value of intellectual freedom is what allows journalists and scholars to publish information that exposes and discredits the actions of those in power, and we must stand in solidarity with them. In addition, we must use our position as advocates to undermine anti-science rhetoric by decentering it and to push back against capitalist structures by focusing on community and collaboration.

\section{Nonviolent Action}

Nonviolent action is a proven strategy for social change (Nagler, 2014). Like sustainability, it centers building relationships and undergoing a shared learning process rather than struggling for power (Nagler, 2014). The goal is not to co-opt power from those who currently hold it, but to dismantle the structures that give them that power. Examples include hosting community conversations about the effects of using fossil fuels, boycotting, and demanding policy changes (Hargar, 2016). Librarians must open those conversations to the public and get both traditional advocacy organizations and small activist groups involved (Henk, 2014). They must partner with community organizations and businesses to encourage dialogue and support them in changing their policies in ways that will have a direct impact. This is an example of the kind of collective action that can be undertaken to fight climate change and climate change denial-community partners and individuals may have different ideas of what the end goal of sustainability is, but so long as they are having conversations and working together, change can be steadily worked toward. 


\section{Creating a Third Space with Indigenous Knowledges}

Indigenous Peoples have been carrying out sustainable practices adapted to their Lands for centuries (Magni, 2017). Indigenous Knowledges have also proven highly valuable in preventing and mitigating the effects of natural disasters, especially with regard to early warning, preparedness, and post-disaster recovery (Rautela \& Karki, 2015). The Intergovernmental Panel on Climate Change identifies Indigenous Knowledges as "major resource[s] for adapting to climate change" (2014, p. 19) and asserts that Indigenous Knowledges should be integrated with existing practices. However, it is not enough to simply state that Indigenous Knowledges are important. Librarians cannot serve as "exemplars, educators, and enablers" of sustainability (IFLA, 2018) if we do not actively seek out Indigenous voices, make the effort to learn for ourselves, and take on the responsibility of educating others.

Glasson, Mhango, Phiri, \& Lanier (2010) use Wallace's notion of the third space to discuss how to work against the subjugation of Indigenous Knowledges by Western modern science. In the third space, neither the speaker nor the listener is "correct", but rather the knowledge shared hopes to co-construct new hybrid meanings (Glasson et al., 2010). Scientific knowledge is a product of culture, and it is impossible to return to a precolonial past. Thus, the use of Indigenous Knowledges to create problem-solving strategies will always have to deal with the effects of colonization and economic globalization (Kincheloe \& Steinberg, 2008). It is therefore vital to engage in dialogue with Indigenous Elders to learn from them and gain a deeper, hybridized understanding of sustainability science-both to help Indigenous Knowledges survive and to provide crucial political allies for effective climate justice movements.

\section{Conclusion}

Libraries serve and support all members of their community, and there is no issue more pressing than the continued ability of those members to live on our planet. Therefore, libraries must envision a sustainable future and take steps to implement it by using their capacity to organize and the tools of power they possess. Furthermore, the profession must acknowledge that because climate change is not a debate and denial of that fact is actively harmful to our society, we should take steps to devalue antiscience rhetoric by decentering it. In order to do so, librarians must ensure access to 
scientific facts about climate change, foster the ability to understand what can be done about it, and build relationships between community members to encourage collective action.

\section{References}

American Library Association. (2017, January 24). Resolution on access to accurate information. http://www.ala.org/advocacy/intfreedom/statementspols/ ifresolutions/accurateinformation

American Library Association. (2019, March 18). Sustainability and libraries. http://www.libguides.ala.org/SustainableLibraries

Barbakoff, A. \& Barbakoff, B. (2012). Building on green: Sustainable thinking goes beyond green to unite library space and community. In M. Antonelli \& M. McCullough (Eds.), Greening Libraries (p. 225-240). Litwin Books.

Glasson, G., Mhango, N., Phiri, A. \& Lanier, M. (2010). Sustainability science education in Africa: Negotiating Indigenous ways of living with nature in the third space. International Journal of Science Education, 32(1), 125-141. https://doi.org/10.1080/09500690902981269

Harger, E. (2016). Charting a new course--ALA and climate crisis. In Which Side Are You On?: Seven Social Responsibility Debates in American Librarianship, 19902015. McFarland.

Hauke, P. (2018). From information literacy to green literacy: Training librarians as trainers for sustainability literacy. In IFLA WLIC 2018. Talk conducted at the meeting of IFLA, Kuala Lumpur, Malaysia. http://library.ifla.org/2147/1/116hauke-en.pdf

Henk, M. (2014). Ecology, Economy, Equity: The Path to a Carbon-neutral Library. ALA Editions.

IFLA. (2018, September 25). Exemplars, educators, enablers: Libraries and sustainability. http://www.ifla.org/files/assets/hq/topics/librariesdevelopment/documents/libraries and sustainability.pdf

Intergovernmental Panel on Climate Change. (2014). Climate Change 2014: Synthesis 
Report - Summary for policymakers. In R. K. Pachauri \& L. A. Meyer (Eds.), Contribution of working groups I, II and III to the Fifth Assessment Report of the Intergovernmental Panel on Climate Change (p. 1-35). Geneva, Switzerland: IPCC. https://www.ipcc.ch/site/assets/uploads/2018/02/

\section{AR5 SYR FINAL SPM.pdf}

Kincheloe, J., \& Steinberg, S. (2008). Indigenous Knowledges in education:

Complexities, dangers, and profound benefits. In N. Denzin, Y. Lincoln, \& L.T. Smith (Eds.), Handbook of Critical and Indigenous Methodologies (p. 135-156). Sage Publications, Inc.

Magni, G. (2017). Indigenous Knowledge and implications for the sustainable development agenda. European Journal of Education, 52(4), 437-447. https://doi.org/10.1111/ejed.12238

Nagler, M. N. (2014). The Nonviolence Handbook: A Guide for Practical Action. Berrett-Koehler Publishers.

Rautela, P., \& Karki, B. (2015). Weather forecasting: Traditional knowledge of the people of Uttarakhand Himalaya. Journal of Geography, Environment and Earth Science International, 3, 1-14. https://doi.org/10.9734/JGEESI/2015/19016

Rich, N. (2018, August 1). Losing earth: The decade we almost stopped climate change. The New York Times Magazine. http://www.nytimes.com/interactive/2018/08/01/magazine/climate-change-losingearth.html

Thiele, L. P. (2016). Sustainability. Polity Press. 